\title{
The effect of maternal depressive symptoms on infant feeding practices in rural Ethiopia: community based birth cohort study
}

Yitbarek Kidane Woldetensay ${ }^{1,2^{*}}$, Tefera Belachew ${ }^{3}$, Shibani Ghosh ${ }^{4}$, Eva Johanna Kantelhardt ${ }^{5,6}$, Hans Konrad Biesalski, ${ }^{1,2}$ and Veronika Scherbaum ${ }^{1}$

\begin{abstract}
Background: Maternal depression and other psychosocial factors have been shown to have adverse consequences on infant feeding practices. This study explored the longitudinal relationship of maternal depressive symptoms and other selected psychosocial factors with infant feeding practices (IFPs) in rural Ethiopia using summary IFP index.

Methods: This study uses existing data from the ENGINE birth cohort study, conducted from March 2014 to March 2016 in three districts in the southwest of Ethiopia. A total of 4680 pregnant women were recruited and data were collected once during pregnancy (twice for those in the first trimester), at birth, and then every 3 months until the child was 12 months old. A standardized questionnaire was used to collect data on IFPs, maternal depressive symptoms, household food insecurity, intimate partner violence (IPV), maternal social support, active social participation, and other sociodemographic variables. A composite measure of IFP index was computed using 14 WHO recommended infant and young child feeding (IYCF) practice indicators. High IFP index indicated best practice. Prenatal and postnatal maternal depressive symptoms were assessed using the patient health questionnaire (PHQ-9). Linear multilevel mixed effects model was fitted to assess longitudinal relationship of IFPs with maternal depression and other psychosocial factors.
\end{abstract}

Results: Reports of higher postnatal depressive symptoms $(B=-1.03, P=0.001)$ and IPV $(B=-0.21, P=0.001)$ were associated with lower scores on the IFP index. Whereas, reports of better maternal social support $(B=0.11, P=0.002)$ and active social participation $(B=0.55, P<0.001)$ were associated with higher scores on the IFP index. Contrary to expectations, moderate household food insecurity $(B=0.84, P=0.003)$, severe household food insecurity $(B=1.03, P=$ 0.01) and infant morbidity episodes ( $B=0.63, P=0.013$ ) were associated with higher scores on the IFP index.

\footnotetext{
* Correspondence: yitbarek.woldetensay@gmail.com

'Institute of Nutrition Science (140a), University of Hohenheim, Stuttgart, Germany

${ }^{2}$ Food Security Center, University of Hohenheim, Stuttgart, Germany

Full list of author information is available at the end of the article
}

C C The Author(s). 2021 Open Access This article is licensed under a Creative Commons Attribution 4.0 International License, which permits use, sharing, adaptation, distribution and reproduction in any medium or format, as long as you give appropriate credit to the original author(s) and the source, provide a link to the Creative Commons licence, and indicate if changes were made. The images or other third party material in this article are included in the article's Creative Commons licence, unless indicated otherwise in a credit line to the material. If material is not included in the article's Creative Commons licence and your intended use is not permitted by statutory regulation or exceeds the permitted use, you will need to obtain permission directly from the copyright holder. To view a copy of this licence, visit http://creativecommons.org/licenses/by/4.0/. The Creative Commons Public Domain Dedication waiver (http://creativecommons.org/publicdomain/zero/1.0/) applies to the data made available in this article, unless otherwise stated in a credit line to the data. 
(Continued from previous page)

Conclusions: Overall, a multitude of factors are related to IFPs and hence coordinated, multi-sectoral and multistakeholder interventions including maternal depressive symptoms screening and management are needed to improve infant feeding practices.

Keywords: Infant feeding practices, Prenatal depression, Postnatal depression, Household food insecurity, Intimate partner violence, Social support, Ethiopia

\section{Background}

According to recent WHO reports, significant global progress has been made in reducing child mortality since 1990 [1]. The global under-5 mortality rate has dropped by $59 \%$ between 1990 and 2018 . However, there are still disparities in under-5 mortality across regions and countries. Sub-Saharan Africa remains the region with the highest rate in the world. Half of all under-five deaths in 2018 occurred in just five countries: India, Nigeria, Pakistan, Ethiopia and the Democratic Republic of Congo. Nutrition-related factors contribute to about $45 \%$ of deaths in children under- 5 years of age [1].

Nutritional deficits during the first 2 years of life are associated with stunting, leading to the adult being shorter than his or her potential height [2]. Adults who were malnourished in early childhood have been found to have impaired intellectual performance, delayed childhood development, reduced capacity for physical work, reduced reproductive capacity and more complicated deliveries in women [3-7]. The first 2 years of life is a critical window of opportunity for prevention of growth faltering and undernutrition through prevention of low birthweight and appropriate infant feeding practices [8].

As the 2005 Innocenti Declaration on infant and young child feeding (IYCF) recognized, appropriate feeding practice during infancy and early childhood is vital for ensuring optimal child health, growth and development [9]. The World Health Organization (WHO) and the United Nations Children's Fund (UNICEF) set a global strategy for optimal IYCF [10]. The Ministry of Health in Ethiopia has also developed and implemented the IYCF guidelines in 2004 [11]. However, IYCF practices are still suboptimal throughout the globe generally and in Ethiopia in particularly [12-17].

Infant feeding practice is a multidimensional and multi-risk factor practice. Sociodemographic related predictors of infant feeding practices are relatively well researched. The literature consistently show that maternal age, socio-economic status, level of education, marital status and location are associated with infant feeding practices [18-24]. However, research examining psychosocial predictors of IFPs are very limited. The limited studies available showed that psychosocial factors were more predictive of IFPs than demographic factors [25-27].
Among the psychosocial factors, prenatal and postnatal depression consistently predicted components of IFPs such as timely breastfeeding initiation i.e. in the first hour of birth [28, 29], exclusive breastfeeding [30-32], breastfeeding duration [33] complementary feeding timely initiation [27] and dietary diversity [34, 35]. Moreover, researchers reported that other psychosocial factors such as intimate partner violence and maternal social support are important predictors of infant feeding practices. While intimate partner violence negatively influences IFPs [36-38], good perceived social support improved appropriate infant feeding practices [39, 40]. On the other hand, several researchers reported intimate partner violence [41-45] and maternal social support [46-49] as positive and negative predictors of maternal depression respectively.

The limited researches available investigating the association between psychosocial factors and IFPs were based on one or two IFP components at a time rather than using child feeding index. This leads to fragmented information and did not show the effect of psychosocial factors on overall feeding patterns. Child feeding index is a composite indicator which allows to measure IYCF practices in their entirety [50-52]. Reinbott et al. reported that a child feeding index is superior to WHO IYCF indicators in explaining length-for-age Z-scores of young children [53]. However, the use of IYCF indices has gained impetus only after early 2000's and to the authors' best knowledge there have been no study that utilized IFP indices to explore the effect of maternal depression on infant feeding practice. Thus, the main objective of this study is to determine the longitudinal association of maternal depressive symptoms and other selected psychosocial factors with IFPs in rural Ethiopia using summary IFP indices.

\section{Methods}

This manuscript is based on ENGINE birth cohort study data. The ENGINE birth cohort study is a prospective, community-based study within Empowering New Generations to Improve Nutrition and Economic opportunities (ENGINE) program. ENGINE was a 5 years nutrition intervention program funded by United States Agency for International Development (USAID) implemented from September 2011 to September 2016 in 100 
selected districts in rural Ethiopia. Its main goal was to improve nutritional status of mothers' and young children through a multi-sectoral approach targeting health, nutrition and agriculture. The program conducted operational researches as part of its rigorous evaluation to generate evidence on program performance and impact. The ENGINE birth cohort study was one of the operational researches conducted under this program. The study was led by Tufts University in partnership with Jimma and Hawassa Universities and Ethiopian Public Health Institute. The study aimed to investigate the benefits of an integrated nutrition program and its colocation with agricultural growth program on household agricultural production and productivity, food security, diet diversity, socio-economic status and livelihoods, as well as health and nutritional status of mothers and their children.

The study had an open cohort design, with recruitment and follow up of pregnant women happened for a period of 2 years. It was conducted from March 2014 to March 2016 in three Districts (Woliso, Tiro-Afeta and Gomma) in the South Western part of Ethiopia. Considering 30\% attrition rate, a total of 4680 pregnant women were recruited between 12 and 32 weeks of gestation. The data was collected at the lowest administrative cluster (Kebele) level. A total of 117 clusters with a total sample size of 40 pregnant women per cluster were included in the study. All Kebeles within a district were sampled, with the exception of a few excluded due to inaccessibility, and a total of 1560 pregnant women were recruited in each of the three districts. In each study Kebele, study participants were recruited consecutively until the quota of 40 pregnant women was achieved. Mothers with serious medical conditions, early pregnancy termination, multiple pregnancies, stillbirth and newborns with congenital anomalies were excluded from the study/follow up.

Data was collected once during pregnancy for all women (twice for those in the first trimester), at birth, and then every 3 months until the child was 12 months old. Data collection was conducted by trained nurses electronically using Open Data Kit (ODK) software on handheld tablets and submitted to a secured server via an internet connection.

\section{Measures \\ Infant feeding practices (IFPs}

Infant feeding index was constructed using data collected at birth and then every 3 months until 12 months of age. Mothers were asked about timing of breastfeeding initiation, colostrum feeding, anything given to the infant before giving breast milk, whether the infant was still breastfed, number of times the infant was breastfed during the day and night yesterday, and what the infant ate yesterday. Based on these information, five separate IFP indices were prepared to assess age-specific infant feeding practices; namely, within 3 days of birth, at 3 months, 6 months, 9 months and 12 months of child age.

The indices were computed following the methods suggested by Ruel and Menon [52]. Each item was scored depending on whether a practice was appropriate based on the WHO infant feeding recommendations $[17,54]$. A practice that was appropriate for a specific age group received a score of 1 , and a practice that was inappropriate received a score of 0 . Practices that are considered particularly relevant for a given time point received a score of 2 or 3 . For example, breastfeeding received a score of 2 for an infant from birth to 12 months of age. A score of 0 was given to non-breastfed infants. Use of bottle with a nipple was scored as 0 because the practice is considered inappropriate for all age groups; avoidance of infant bottles received a score of 1 , indicating an appropriate practice. The dietary diversity score was calculated by adding the number of food groups consumed in the last $24 \mathrm{~h}$ and received a score of 0 if the child got below three food groups, 1 if the child got three food groups, and scored 2 if the child got four or more than four food groups in the past $24 \mathrm{~h}$ (Table 1).

The unstandardized total score could reach a maximum of 9-15 scoring points depending on the time point. The indices were standardized by converting each score into percentage of the maximum total score of the scales at each time point. A higher score in the feeding scales indicated a better infant feeding practice. The index was treated as continues variable. Table 1 below depicts the infant feeding practice variables and scoring system used in this paper.

\section{Maternal depressive symptoms}

Maternal depressive symptoms were assessed using the Patient Health Questionnaire (PHQ-9) [55]; once during pregnancy for all women (twice for those in the first trimester), within $72 \mathrm{~h}$ after birth and 3 months postpartum. The PHQ-9 is a 9-item self-administered questionnaire designed to evaluate the presence of depressive symptoms during the prior 2 weeks. The nine items of the PHQ-9 are based directly on the nine diagnostic criteria for major depressive disorder in the DSM-IV (Diagnostic and Statistical Manual Fourth Edition) [56]. Each of the nine items can be scored from 0 (not at all) to 3 (nearly every day). Thus, the total score can range from 0 (absence of depressive symptoms) to 27 (most severe depressive symptoms).

The PHQ-9 scale had been validated for Afaan Oromo Language in a similar population prior to the commencement of the ENGINE birth cohort study and possessed good psychometric properties. A PHQ-9 score of 8 or 
Table 1 Feeding practice variables and scoring system used to construct the infant feeding practice index, Ethiopia, 2019

\begin{tabular}{|c|c|c|c|c|c|}
\hline \multirow[t]{2}{*}{ IYCF indicators } & \multicolumn{5}{|l|}{ Scoring } \\
\hline & Birth & 3 months & 6 months & 9 months & 12 months \\
\hline \multirow[t]{3}{*}{ Timely Initiation of breastfeeding } & $0=$ after 1 day & & & & \\
\hline & $1=$ within $24 \mathrm{~h}$ & & & & \\
\hline & $2=$ within an hour & & & & \\
\hline \multirow[t]{2}{*}{ Prelacteal feeding } & $0=$ Yes & & & & \\
\hline & $1=\mathrm{No}$ & & & & \\
\hline \multirow[t]{2}{*}{ Colostrum feeding } & $0=\mathrm{No}$ & & & & \\
\hline & $1=$ Yes & & & & \\
\hline \multirow[t]{2}{*}{ Exclusive breastfeeding } & $0=\mathrm{No}$ & $0=\mathrm{No}$ & & & \\
\hline & $2=$ Yes & $2=$ Yes & & & \\
\hline \multirow[t]{4}{*}{ Frequency of breastfeeding per day } & $\begin{array}{l}0=\mathrm{No} \\
\text { breastfeeding }\end{array}$ & $\begin{array}{l}0=\mathrm{No} \\
\text { breastfeeding }\end{array}$ & $\begin{array}{l}0=\text { No } \\
\text { breastfeeding }\end{array}$ & $0=$ No breastfeeding & $0=$ No breastfeeding \\
\hline & $\begin{array}{l}1=\text { less than } 8 \\
\text { times }\end{array}$ & $\begin{array}{l}1=\text { less than } 8 \\
\text { times }\end{array}$ & $\begin{array}{l}1=\text { less than } 8 \\
\text { times }\end{array}$ & $1=$ less than 8 times & $1=$ less than 8 times \\
\hline & $2=8-11$ times & $2=8-11$ times & $2=8-11$ times & $2=8-11$ times & $2=8-11$ times \\
\hline & $3=\geq 12$ times & $3=\geq 12$ times & $3=\geq 12$ times & $3=\geq 12$ times & $3=\geq 12$ times \\
\hline \multirow[t]{2}{*}{ Continued Breastfeeding at 1 year } & $0=\mathrm{No}$ & $0=\mathrm{No}$ & $0=\mathrm{No}$ & $0=\mathrm{No}$ & $0=\mathrm{No}$ \\
\hline & $1=$ Yes & $1=$ Yes & $1=$ Yes & $1=$ Yes & $1=$ Yes \\
\hline \multirow[t]{2}{*}{ Bottle feeding } & $0=$ Yes & $0=$ Yes & $0=$ Yes & $0=$ Yes & $0=$ Yes \\
\hline & $1=\mathrm{No}$ & $1=\mathrm{No}$ & $1=\mathrm{No}$ & $1=\mathrm{No}$ & $1=\mathrm{No}$ \\
\hline \multirow{2}{*}{$\begin{array}{l}\text { Introduction of solid/semi-solid/soft } \\
\text { food }\end{array}$} & $0=$ Yes & $0=$ Yes & $0=\mathrm{No}$ & $0=\mathrm{No}$ & $0=\mathrm{No}$ \\
\hline & $1=\mathrm{No}$ & $1=\mathrm{No}$ & $2=$ Yes & $2=$ Yes & $2=$ Yes \\
\hline \multirow[t]{3}{*}{ Minimum dietary diversity } & & & & $\begin{array}{l}0=\text { less than } 3 \text { food } \\
\text { types }\end{array}$ & $\begin{array}{l}0=\text { less than } 3 \text { food } \\
\text { types }\end{array}$ \\
\hline & & & & $1=$ only 3 food types & $1=$ only 3 food types \\
\hline & & & & $\begin{array}{l}2=4 \& \text { more food } \\
\text { types }\end{array}$ & $\begin{array}{l}2=4 \& \text { more food } \\
\text { types }\end{array}$ \\
\hline \multirow[t]{3}{*}{ Minimum meal frequency } & & & & $0=$ no food taken & $0=$ no food taken \\
\hline & & & & $1=1-2$ times a day & $1=1-2$ times a day \\
\hline & & & & $2=3$ or more times & $2=3$ or more times \\
\hline \multirow[t]{2}{*}{ Minimum acceptable diet } & & & & $0=\mathrm{No}$ & $0=\mathrm{No}$ \\
\hline & & & & $1=$ Yes & $1=$ Yes \\
\hline \multirow[t]{2}{*}{ Consumption of iron rich food } & & & & $0=\mathrm{No}$ & $0=\mathrm{No}$ \\
\hline & & & & $1=$ Yes & $1=$ Yes \\
\hline \multirow[t]{2}{*}{ On demand BF } & $0=\mathrm{No}$ & $0=\mathrm{No}$ & $0=\mathrm{No}$ & $0=\mathrm{No}$ & $0=\mathrm{No}$ \\
\hline & $1=$ Yes & $1=$ Yes & $1=$ Yes & $1=$ Yes & $1=$ Yes \\
\hline \multirow[t]{2}{*}{ Active feeding } & & & $0=\mathrm{No}$ & $0=\mathrm{No}$ & $0=\mathrm{No}$ \\
\hline & & & $1=$ Yes & $1=$ Yes & $1=$ Yes \\
\hline Potential score & $0-13$ & $0-9$ & $0-9$ & $0-15$ & $0-15$ \\
\hline
\end{tabular}

above was taken as a cut off to define depressive symptoms [57]. For this study maternal depressive symptoms were classified as prenatal, postnatal and persistent. Only few mothers have time point two data and hence only time point one depressive symptoms data were used to define prenatal depressive symptoms. Depressive symptoms measured within 3 days of birth were used to define postnatal depressive symptoms. Whereas, persistent depressive symptoms were defined as mothers screened positive for depressive symptoms during all the three assessment periods; during pregnancy, at birth and 3 months postpartum. Only $1.2 \%$ of the participating women had persistent depressive symptoms and this category of depressive symptoms was not considered in the final model. 


\section{Household food insecurity}

The household food insecurity was measured using the Household Food Insecurity Access Scale [58] at baseline (recruitment), at infants 6 months and 12 months of age. For this article we used the baseline measurement. The index women were asked nine questions (yes/no) to determine if anyone in their household had experienced problems of food access over 4 weeks preceding the interview. An affirmative response to any of the nine questions was followed by a question to determine how often the condition happened: rarely (1-2 times), sometimes (3-10 times), and often (>10 times). Responses were coded as $0=$ never (i.e., no experience), $1=$ rarely, $2=$ sometimes, or $3=$ often. Household food insecurity was categorized into four severity levels: food secure, mildly food insecure, moderately food insecure, and severely food insecure as per the algorithm described by Coates et al. [58].

\section{Intimate partner violence (IPV)}

A screening tool called HITS (Hurt, Insult, Threaten and Scream) was applied to assess intimate partner violence [59]. This data was collected from mothers within 3 days of birth. The scale has four items and each item was scored on a scale of 1 (never) to 5 (frequently) with total score of 20 possible. Then, sum score was computed and treated as a continuous variable in the model.

\section{Maternal social support}

Maternal Social support was measured using the Maternity Social Support Scale (MSSS) developed by Webster and colleagues [60] within 3 days of birth. The scale contains six items. Each item has measured on a five-point Likert scale of 1 (never) to 5 (frequently) and a total score of 30 was possible. Similarly, the score was treated as continuous variable in this study where a high score corresponds with a high level of perceived social support.

\section{Sociodemographic characteristics}

Educational status of the mother was categorized into four as illiterate, primary, junior and secondary and above for analysis purpose. Marital status was dichotomized into married (married monogamous and married polygamous) and unmarried (single, widowed, divorced, and separated). Religion was categorized into three as Muslim, Protestant, and Catholic \& Orthodox. Similarly, mothers' age was categorized as $<25$ years, $25-35$ years and above 35 years. Gestational age at birth was dichotomized as term (37 weeks and above) and preterm $(<37$ weeks). Birthweight dichotomized as normal (2500 g and above) and low birthweight $(<2500 \mathrm{~g})$; however, birthweight was treated as a continuous data in the model. A wealth index was created following the methods described by the Demographic and Health Surveys for Ethiopia [21] using polychoric principal component analysis to represent a composite measure of a household's cumulative living conditions and then separated into quintiles.

\section{Statistical analysis}

We examined whether missing data on feeding practices and maternal depressive symptoms differed from those who were not missing these data. We compared these two groups on infants' birth weight, household food security, and other key baseline sociodemographic variables. For the continuous variables, we used a $t$ test for equality of means, and, for the categorical variables, we used Pearson's chi-square tests.

Participants' characteristics, IFPs and maternal depressive symptoms were summarized using descriptive statistics. To assess longitudinal relationship of infant feeding practice (IFP) and maternal depressive symptoms, we assumed that the repeated measurements of IFPs taken from each infant, overtime, are correlated and it is expected that study participants changed feeding practices over time as infants gets older. To examine differences in IFP within individual subjects over the follow up period, a linear multilevel mixed effects (fixed effects and random effects) model with a random intercept and a random slope was fitted with maximum likelihood estimation method. The fixed effects describe a population intercept and population slopes for a set of covariates, which include exposures and potential confounders. Random effects describe individual variability in IFP and changes over time. By considering individual random slopes and intercepts, this model allows to examine the influence of covariates on the change in IFP over time. Subjects with IFP data from at least two assessment intervals were included in the analysis.

\section{Results}

Missing data and attrition

Of the total 4680 pregnant women recruited and followed-up, 1090 study participants (23.3\%) were lost to follow-up between recruitment and 12 months' postpartum. The most lost to follow up (47.7\% of the total lost to follow) occurred at time point three. The main reasons for the lost to follow-up were stillbirths (3.3\%), infant death unrelated to the study (3.0\%), twin pregnancy (1.3\%), abortion $(0.9 \%)$ and others such as relocation, refusal to continue participation, and absence during data collection after three repeated trial (6.7\%). The data collection was stopped before $378(8.1 \%)$ of the infants reached 12 months of age and hence time point seven data missed for these participants. Potential biases related to missing data were assessed based on infant and maternal demographic and socio-economic characteristics. Study participants 
with missing data on maternal depression and IFPs did not differ from participants with complete data on basic sociodemographic or other study variables.

\section{Characteristics of the study participants}

Characteristics of the study participants are presented in Table 2 below. The median age of study participants at the time of recruitment was 26 years (inter-quartile range $[\mathrm{IQR}] 22,30)$. More than half of the pregnant women (55.2\%) were illiterate and only $241(5.1 \%)$ of the respondents had completed secondary education or higher. Just over two-third (67.3\%) of the respondents were Muslim and $97.7 \%$ were married. The infant girls were slightly higher than boys in number. Over $95 \%$ of the infants were normal birthweight (weighing greater than $2.5 \mathrm{~kg}$ ), however, more than a third of them were born preterm. In terms of morbidity, $57.5 \%$ of babies were ill at least once during the infancy period (Table 2).

\section{Infant feeding practices}

Patterns of IFPs are presented in Table 3 below. The findings of the present study demonstrated that in Ethiopia infant feeding practices is generally poor, especially after the first 6 months of age. Dietary diversity and consumption of iron rich foods are particularly unacceptable low. However, majority of mothers follow the WHO recommended breastfeeding practices; namely, early initiation of breastfeeding, colostrum feeding, prelacteal feeding, exclusive breastfeeding and continued breastfeeding at 1 year are relatively better (Table 3 ).

The study shows that considerable number of infants were exclusively fed only breast milk beyond 6 months of age. Using the 24-h recall methods, $14.6 \%(n=683)$ and $11.3 \%(n=530)$ of infants at nine and 12 months of age respectively, were still exclusively fed breast milk. However, when plausibility was checked against introduction of solid and semi-solid food and exclusive breastfeeding status during the previous assessments (time points), this prevalence reduced to $1.6 \%(n=64)$ and $0.1 \%(n=3)$ at nine and 12 months in that order.

\section{Maternal depressive symptoms prevalence}

Among women who screened for depressive symptoms, cumulative incidence proportions were 10.8, 18.5 and $7.5 \%$ during pregnancy, within 3 days after birth and 3 months' postpartum, respectively. Overall, 1156 (26.2\%) of the mothers had depressive symptoms at least once during the period between recruitment and 3 months' postpartum and 56 respondents $(1.2 \%)$ were having depressive symptoms persistently during the three measurement times. PHQ-9 mean scores (standard deviation) during the three occasions were 3.11 (4.53), 4.35 (4.04) and 2.13 (3.20) respectively.

\section{Longitudinal relationship of IFP and maternal depressive symptoms}

Based on the standardized composite indices of IFP, the poorest IFP practice occurred at 6 months of infancy (only $54 \%$ of the potential score). The practice was better during the first 6 months than the second half of the infancy period (Table 4).

As presented in Table 5, linear mixed effects model showed that postnatal maternal depressive symptoms were negatively associated with IFPs $(P=0.001)$. However, prenatal maternal depressive symptoms were not associated with IFPs $(P=0.953)$. Similar to postnatal depressive symptoms, intimate partner violence was negatively associated with IFPs $(P=0.001)$. On the other hand, maternal social support $(P=0.002)$ and social participation $(P<0.001)$ were positively associated with infant feeding practices. Compared with Orthodox Christians, Protestant \& Catholic Christians have better IFPs scores $(P=0.002)$ but infants from Muslim families have poorer IFP scores $(P<0.001)$. Contrary to expected, moderate household food insecurity $(P=0.003)$, severe household food insecurity $(P=0.01)$ and infant morbidity episodes $(P=0.013)$ were positively associated with infant feeding practices. Maternal education and gestational age at birth were other important factors positively associated with IFPs in this study.

\section{Discussion}

In this study we examined the association between maternal depressive symptoms and other psychosocial factors with IFPs using a computed index suggested by Ruel and Menon [52]. The key contribution of this study is to show the effect of maternal depressive symptoms and other psychosocial factors on IFPs in rural Ethiopia. The current findings demonstrated that postnatal depressive symptoms and intimate partner violence predicted poor infant feeding practices. The findings also show that strong maternal social support and active social participation were associated with better infant feeding practices. These findings have important implications for policy makers, researchers, donors and program implementers working on child nutrition in Ethiopia, where the burden of child malnutrition is the highest [14].

A statistically significant negative association was found between postnatal depressive symptoms and overall IFP score in this study. So far, only a few studies have used IFP index in feeding practice studies and to the researchers' best knowledge there is no study which explores the longitudinal relationship between IFPs and maternal depressive symptoms using an IFP index. However, several previous observational studies reported that maternal postnatal depression is associated with specific components of IFPs, though, the direction of 
Table 2 Characteristics of study participants, Ethiopia, 2019

\begin{tabular}{|c|c|c|}
\hline Variables & Number & Percent \\
\hline \multicolumn{3}{|l|}{ Maternal age } \\
\hline Less than 25 years & 1615 & 34.5 \\
\hline 25-35 years & 2831 & 60.5 \\
\hline Above 35 years & 234 & 5.0 \\
\hline Median (IQR) & $26(22-30)$ & \\
\hline \multicolumn{3}{|l|}{ Religion } \\
\hline Orthodox & 1057 & 22.6 \\
\hline Protestant \& Catholic & 472 & 10.1 \\
\hline Muslim & 3148 & 67.3 \\
\hline \multicolumn{3}{|c|}{ Maternal educational status } \\
\hline Illiterate & 2585 & 55.2 \\
\hline Primary & 1491 & 31.9 \\
\hline Junior & 363 & 7.8 \\
\hline Secondary \& above & 241 & 5.1 \\
\hline \multicolumn{3}{|l|}{ Marital status } \\
\hline Married & 4572 & 97.7 \\
\hline Unmarried & 108 & 2.3 \\
\hline \multicolumn{3}{|l|}{ Infants gender } \\
\hline Male & 2252 & 49.7 \\
\hline Female & 2276 & 50.3 \\
\hline \multicolumn{3}{|l|}{ Birthweight } \\
\hline Normal birth weight & 3972 & 95.6 \\
\hline Low birth weight & 183 & 4.4 \\
\hline \multicolumn{3}{|l|}{ Gestational age at birth } \\
\hline Preterm & 1442 & 34.7 \\
\hline Term & 2717 & 65.3 \\
\hline \multicolumn{3}{|c|}{ Child illness during the infancy period } \\
\hline Yes & 2690 & 57.5 \\
\hline No & 1990 & 42.5 \\
\hline \multicolumn{3}{|l|}{ Antenatal care } \\
\hline No ANC & 1626 & 34.8 \\
\hline 1-3 ANC visits & 1194 & 25.5 \\
\hline 4 plus visits & 1859 & 39.7 \\
\hline \multicolumn{3}{|l|}{ Place of delivery } \\
\hline Health facility & 2934 & 66.4 \\
\hline TBA & 75 & 1.7 \\
\hline Home & 1345 & 30.4 \\
\hline Other & 66 & 1.5 \\
\hline \multicolumn{3}{|l|}{ Birth complication } \\
\hline Yes & 927 & 19.8 \\
\hline No & 3753 & 80.2 \\
\hline \multicolumn{3}{|c|}{ History of spontaneous abortion } \\
\hline Yes & 539 & 11.5 \\
\hline No & 4140 & 88.5 \\
\hline
\end{tabular}

Table 2 Characteristics of study participants, Ethiopia, 2019 (Continued)

\begin{tabular}{|c|c|c|}
\hline Variables & Number & Percent \\
\hline \multicolumn{3}{|l|}{ History of child death } \\
\hline Yes & 1213 & 25.9 \\
\hline No & 3466 & 74.1 \\
\hline \multicolumn{3}{|c|}{ Intimate partner violence (total score > 10) } \\
\hline Yes & 417 & 8.9 \\
\hline No & 4263 & 91.1 \\
\hline \multicolumn{3}{|l|}{ Maternal social support } \\
\hline Good & 2631 & 56.2 \\
\hline Poor & 2049 & 43.8 \\
\hline \multicolumn{3}{|c|}{ Maternal social participation } \\
\hline Yes & 2886 & 61.7 \\
\hline No & 1794 & 38.3 \\
\hline \multicolumn{3}{|l|}{ Household food insecurity } \\
\hline Secured & 1600 & 34.2 \\
\hline Mildly insecure & 600 & 12.8 \\
\hline Moderately insecure & 1846 & 39.4 \\
\hline Severely insecure & 634 & 13.5 \\
\hline \multicolumn{3}{|l|}{ Wealth index } \\
\hline Lowest & 928 & 19.8 \\
\hline Second & 957 & 20.4 \\
\hline Middle & 863 & 18.4 \\
\hline Fourth & 986 & 21.1 \\
\hline Highest & 934 & 20.0 \\
\hline
\end{tabular}

association between breastfeeding and postpartum depression remains unclear [61]. Systematic reviews in 2019 and 2015 concluded that depressed women breastfed their children for shorter duration than nondepressed women [30, 31]. Other previous studies also reported a negative association of maternal depression with early initiation of breastfeeding [28], timely complementary feeding initiation [27] and infants' dietary diversity [34, 35].

Infants born to women who experienced intimate partner violence were at greater risk of poor infant feeding practices. This finding is consistent with previous studies [36-38] and has important implications, particularly in Ethiopia, where $34 \%$ of ever-married women experienced such violence [14]. There are many pathways through which intimate partner violence can affect infant feeding practices [62]. First, IPV is a stressor which leads to depression [42, 63, 64]. As stated above, maternal depression leads to poor infant feeding practices [31]. IPV can also indirectly affect IFPs by influencing mothers' exposure to antenatal care services [65] and hence access to nutrition related counseling. Studies have suggested that in resource limited settings quality 
Table 3 Core infant feeding practices, Ethiopia, 2019

\begin{tabular}{|c|c|c|c|}
\hline \multicolumn{2}{|l|}{ Infant feeding practices indicators } & \multirow[t]{2}{*}{ Number } & \multirow[t]{2}{*}{ Percent } \\
\hline Core indicators & & & \\
\hline Timely Initiation of breastfeeding & Within an hour & 3031 & 72.5 \\
\hline & Within $24 \mathrm{~h}$ & 1048 & 25.1 \\
\hline & After 1 day & 100 & 2.4 \\
\hline \multirow[t]{2}{*}{ Exclusive breastfeeding at: } & Within 3 days of birth & 4097 & 97.2 \\
\hline & 3 months & 2936 & 89.3 \\
\hline Continued breastfeeding at 1 year & & 3531 & 99.6 \\
\hline \multirow[t]{5}{*}{ Introduction of solid/semi-solid/soft food at: } & Within 3 days of birth & 8 & 0.2 \\
\hline & 3 months & 217 & 5.2 \\
\hline & 6 months & 1707 & 42.1 \\
\hline & 9 months & 3605 & 90.2 \\
\hline & 12 months & 3442 & 95.7 \\
\hline \multirow[t]{3}{*}{ Minimum dietary diversity at: } & 6 months & 13 & 0.8 \\
\hline & 9 months & 27 & 0.7 \\
\hline & 12 months & 88 & 2.6 \\
\hline \multirow[t]{3}{*}{ Minimum meal frequency at: } & 6 months & 1405 & 82.5 \\
\hline & 9 months & 1914 & 53.1 \\
\hline & 12 months & 2158 & 62.7 \\
\hline \multirow[t]{3}{*}{ Minimum acceptable diet at: } & 6 months & 4 & 0.4 \\
\hline & 9 months & 12 & 0.3 \\
\hline & 12 months & 16 & 0.3 \\
\hline \multirow[t]{3}{*}{ Consumption of iron rich food } & 6 months & 4 & 0.2 \\
\hline & 9 months & 12 & 0.3 \\
\hline & 12 months & 16 & 0.3 \\
\hline \multicolumn{4}{|l|}{ Optional indictors } \\
\hline \multicolumn{4}{|l|}{ Frequency of breastfeeding at: } \\
\hline \multirow[t]{3}{*}{ Within 3 days of birth } & $<8$ months & 1007 & 24.6 \\
\hline & 8-11 months & 1880 & 46.0 \\
\hline & $>=12$ months & 1200 & 29.4 \\
\hline \multirow[t]{3}{*}{3 months } & $<8$ months & 340 & 8.3 \\
\hline & $8-11$ months & 1802 & 44.2 \\
\hline & $>=12$ months & 1935 & 47.5 \\
\hline \multirow[t]{3}{*}{6 months } & $<8$ months & 470 & 11.8 \\
\hline & 8-11 months & 1753 & 44.0 \\
\hline & $>=12$ months & 1766 & 44.3 \\
\hline \multirow[t]{3}{*}{9 months } & $<8$ months & 624 & 15.9 \\
\hline & $8-11$ months & 1907 & 48.5 \\
\hline & $>=12$ months & 1397 & 35.6 \\
\hline \multirow[t]{3}{*}{12 months } & $<8$ months & 864 & 24.6 \\
\hline & 8-11 months & 1669 & 47.5 \\
\hline & $>=12$ months & 976 & 27.8 \\
\hline Colostrum feeding & & 3653 & 87.4 \\
\hline Prelacteal feeding & & 36 & 0.9 \\
\hline Bottle feeding & Within 3 days of birth & 136 & 3.1 \\
\hline
\end{tabular}


Table 3 Core infant feeding practices, Ethiopia, 2019 (Continued)

\begin{tabular}{|c|c|c|c|}
\hline Infant feeding practices indicators & & Number & Percent \\
\hline & 3 months & 635 & 15.2 \\
\hline & 6 months & 1394 & 34.4 \\
\hline & 9 months & 1406 & 35.2 \\
\hline & 12 months & 992 & 27.6 \\
\hline \multirow[t]{5}{*}{ On demand BF } & Within 3 days of birth & 3280 & 78.3 \\
\hline & 3 months & 2662 & 64.4 \\
\hline & 6 months & 2189 & 54.4 \\
\hline & 9 months & 1765 & 44.6 \\
\hline & 12 months & 1321 & 37.3 \\
\hline \multirow[t]{3}{*}{ Active feeding } & 6 months & 972 & 56.9 \\
\hline & 9 months & 2114 & 58.6 \\
\hline & 12 months & 2050 & 59.6 \\
\hline
\end{tabular}

prenatal and delivery care services significantly increase early initiation and duration of exclusive breastfeeding in the first 6 months of life [66]. According to WHO, women who suffer from IPV face social problems, lack of family support, restricted access to services, strained relationships with health care providers and employers, and isolation from social networks [67]. As a result, affected mothers initiate prenatal care later or receive inadequate care or no antenatal care at all $[68,69]$. Another pathway could be that mothers with low selfesteem or lack of confidence as a consequence of IPV [70] are also less likely to exercise adequate infant feeding practices [71].

Contrary to many of previous studies, we found that infants in moderately and severely food insecure households rather have better IFP scores. Several previous studies reported that household food insecurity was negatively associated with infant feeding practices [72, 73]. However, the direction of the association does not mean that all infants in food secure households received appropriate and adequate feeding. In Uganda, Pascal et al. found that eight out of 10 infants in food secure households were not receiving the minimum dietary diversity required and reported that household food insecurity explains only $10 \%$ of the variance of dietary quality determinants [74]. Conversely, our finding agrees with the studies in
Kenya and Tanzania [75, 76]; both studies concluded that infants from food insecure households were less likely to receive cow milk before they reached 6 months. Particularly in Kenya, dairy producing households had a 12-fold increased risk for exclusive breastfeeding interruption by early animal milk introduction compared to those in households without cattle.

Another probable reason for the positive association between food insecurity and IFPs in this study could be ENGINE program vulnerable households focused IYCF interventions. ENGINE end-line impact assessment reported that the program achieved over 10 percentage point increase in infant and child feeding index (ICFI) in $50 \%$ of intervention Districts [77]. Studies showed that IYCF focused nutrition education for caregivers improved child dietary diversity and nutrition knowledge of caretakers even in food insecure areas [78, 79]. Moreover, as we indicated earlier, the IFP scores were relatively higher during the first 6 months than the second half of infancy; during the first 6 months, the IFP elements are more amenable to improve by IYCF focused social and behavior change communications costing no or minimal resources for a rural mother.

In this study, only half of women reported that they feel they have good social support during pregnancy $(43.8 \%)$ and postpartum period (56.2\%). We found

Table 4 Descriptive statistics of infant feeding practices by infants' age, Ethiopia, 2019

\begin{tabular}{lllll}
\hline $\begin{array}{l}\text { Time } \\
\text { point }\end{array}$ & Subject & $\begin{array}{l}\text { Potential } \\
\text { score }\end{array}$ & & Mean, SD (Range) \\
\cline { 4 - 5 } & & $0-13$ & Unstandardized & Standardized \\
\hline Birth & 4023 & $0-9$ & $10.4 \pm 1.1(5-13)$ & $79.7 \pm 8.6(38.5-100)$ \\
6 months & 3120 & $0-10$ & $7.3 \pm 1.5(2-9)$ & $81.5 \pm 17.0(22.2-100)$ \\
6 months & 3987 & $0-15$ & $5.4 \pm 1.3(2-10)$ & $53.9 \pm 12.9(20.0-100)$ \\
9 months & 3543 & $0-13$ & $8.5 \pm 1.3(5-14)$ & $56.5 \pm 8.9(33.3-93.3)$ \\
12 months & 3355 & $7.4 \pm 1.2(4-12)$ & $56.7 \pm 9.6(30.8-92.3)$ \\
\hline
\end{tabular}


Table 5 Multilevel model results of the association between infant feeding practices and maternal depressive symptoms and other predictors, Ethiopia, 2019

\begin{tabular}{|c|c|c|c|c|c|}
\hline Factors & $\beta$ & $95 \% \mathrm{Cl}$ & & $P$-value & SE \\
\hline Maternal age & 0.010 & -0.036 & 0.057 & 0.66 & 0.024 \\
\hline \multicolumn{6}{|l|}{ Mother Education } \\
\hline \multicolumn{6}{|l|}{ Illiterate } \\
\hline Primary & 0.787 & 0.240 & 1.333 & 0.005 & 0.279 \\
\hline Secondary \& above & 1.357 & 0.567 & 2.146 & 0.001 & 0.403 \\
\hline \multicolumn{6}{|l|}{ Religion } \\
\hline \multicolumn{6}{|l|}{ Orthodox } \\
\hline Protestant \& Catholic & 1.497 & 0.548 & 2.447 & 0.002 & 0.484 \\
\hline Muslim & -2.587 & -3.209 & -1.965 & $<0.001$ & 0.317 \\
\hline Wealth index & -0.007 & -0.073 & 0.060 & 0.844 & 0.034 \\
\hline \multicolumn{6}{|l|}{ Household food security } \\
\hline \multicolumn{6}{|l|}{ Secured } \\
\hline Mildly insecure & -0.692 & -1.458 & 0.073 & 0.076 & 0.391 \\
\hline Moderately insecure & 0.836 & 0.293 & 1.380 & 0.003 & 0.277 \\
\hline Severely insecure & 1.034 & 0.251 & 1.816 & 0.01 & 0.399 \\
\hline \multicolumn{6}{|l|}{ Prenatal Depression } \\
\hline Yes & -0.024 & -0.802 & 0.755 & 0.953 & 0.397 \\
\hline \multicolumn{6}{|l|}{ No } \\
\hline \multicolumn{6}{|l|}{ Postnatal Depression (within 3 days of birth) } \\
\hline Yes & -1.031 & -1.647 & -0.414 & 0.001 & 0.314 \\
\hline \multicolumn{6}{|l|}{ No } \\
\hline Maternal social support & 0.107 & 0.041 & 0.174 & 0.002 & 0.034 \\
\hline Social participation & 0.552 & 0.298 & 0.806 & $<0.001$ & 0.129 \\
\hline Intimate partner violence & -0.208 & -0.337 & -0.080 & 0.001 & 0.065 \\
\hline \multicolumn{6}{|l|}{ Child gender } \\
\hline \multicolumn{6}{|l|}{ Male } \\
\hline Female & -0.128 & 0.580 & 0.326 & 0.58 & 0.232 \\
\hline Gestational age at birth & 0.517 & 0.035 & 0.998 & 0.036 & 0.246 \\
\hline \multicolumn{6}{|l|}{ Antenatal care visits } \\
\hline \multicolumn{6}{|l|}{ No ANC } \\
\hline 1-3 ANC visits & -0.418 & -1.023 & 0.186 & 0.175 & 0.309 \\
\hline 4 plus visits & 0.261 & -0.325 & 0.847 & 0.382 & 0.299 \\
\hline \multicolumn{6}{|l|}{ Child illness } \\
\hline Yes & 0.625 & 0.134 & 1.117 & 0.013 & 0.251 \\
\hline \multicolumn{6}{|l|}{ No } \\
\hline Constant & 67.389 & 64.723 & 70.054 & $<0.001$ & 1.360 \\
\hline \multicolumn{6}{|l|}{ Random-effects } \\
\hline Variance of random intercept & 7.208 & 6.971 & 7.453 & & 0.123 \\
\hline Variance of random slope & 24.743 & 23.741 & 25.789 & & 0.522 \\
\hline Covariance of random intercept and slope & -0.998 & -0.999 & -0.994 & & 0.001 \\
\hline Variance of measurement errors & 13.29416 & 13.09836 & 13.49288 & & 0.10064 \\
\hline
\end{tabular}

SE standard error 
that maternal social support was positively associated with infant feeding practices. In agreement with our findings, previous studies reported that maternal social support helps mothers to practice appropriate infant and young child feeding [39, 40]. Similarly, our study revealed that infants whose mothers actively participated in social groups have a better IFP scores than those with poor participation. Previous studies consistently reported that social participation is associated with mental and physical health benefits. Seeman and colleagues found that having three or more regular social contacts, as opposed to zero to two such contacts, is associated with lower allostatic load scores [80]. Lower allostatic load mean lower depression [81, 82] and then better IFP scores. In Ethiopia social groups are main platforms to reach mothers with IYCF messages [83].

Gestational age at birth was positively associated with IFP scores. This implies that preterm infants were not receiving good IFPs compared to their full term counterparts. Consistent with our findings, previous studies reported that mothers of preterm infants initiated breastfeeding late and that preterm infants are breastfed for a shorter duration [84-86]. Similarly, observational studies in Italy and the United Kingdom reported early introduction of solid foods with a majority of preterm infants receiving a solid food prior to 4 months of age [87, 88].

A systematic review by Kajali and Vector revealed that restriction or interruption of complementary foods during illness is frequent because of children's anorexia, poor awareness by caregivers' about the feeding needs of sick children, traditional beliefs and behaviors, and/or suboptimal counselling and support by health workers [89]. However, we found that infants with higher morbidity episodes have higher IFP scores too. We presumed that frequent episodes of illness increase mothers' frequency of contact with health care providers and hence repetitive IYCF counseling which improves mothers' IYCF awareness and practices. Abegaze and colleagues reported that in Ethiopia mothers with prior experience of infant illness were more likely to seek healthcare for their sick children than their counterparts [90]. Moreover, as a sick infant loses its appetite, mothers could frequently serve different type of foods to the infant that potentially increases diet diversity and/or frequency and increase the IFP scores.

Mothers with primary and above school qualification seemed to perform better with respect to IFPs than illiterate mothers. This finding is in agreement with previous studies in Ethiopia and elsewhere [13, 28, 34, 35, 91]. This may be explained by educated mothers having better understanding of IYCF itself and/or had exposure to IYCF awareness raising campaigns (through their ability to read leaflets, posters and banners), that have been conducted for several years by the Ministry of Health and development partners in Ethiopia.

The IFPs score is relatively higher during the first 6 months than the second 6 months of age. During the first 6 months, IFP components need no significant additional costs for rural Ethiopian women but mothers' commitment and knowledge. However, during the second 6 months of the infancy period, the IFP components need resources particularly to fulfill the required quality of meal and the frequency. As revealed in this study, less than $3 \%$ of infants received a quality diet as measured by dietary diversity. Several previous studies in Ethiopia came up with similar findings of unacceptably low percentage of infant dietary diversity [22, 92-94]. Moreover, we found that the IFP score was the poorest particularly at 6 months of age. This might be explained by the small proportion of mothers who practiced timely initiation of complementary feeding in this study. Besides, 6-8 months of infancy is the transition period where mothers/caretakers teach babies to take solid and semi-solid foods.

In this study, using 24-h recall methods, more than 10 $\%$ of infants were exclusively feed only breast milk beyond 6 months of age. However, this proportion has substantially dropped when plausibility was checked against introduction of solid/semi-solid/soft food or liquid and exclusive breastfeeding status during the previous assessments (time points). Previous researchers have commented on the drawbacks of the 24-h recall method that it misclassifies too many mothers as exclusively breastfeeding and suggested several techniques that needs to be taken during data collection to minimize the problem [95-98]. Based on our findings, for longitudinal studies, plausibility check against introduction of solid/semisolid or liquid other than breast milk during previous time points could be used as one option to reduce the downside of point-in-time or current status exclusive breastfeeding measurements (24-h recall).

One of the main strengths of this study is that it is based on community based longitudinal data (prospective birth cohort) with appropriate analytical techniques applied. The study had a large sample size, high response rate and low attrition. Data were collected on regular intervals on several important sociodemographic, nutritional and clinical risk factors that could be harvested for this analysis. In addition, we used $14 \mathrm{WHO}$ recommended IYCF core and optional indicators to compute the IFP score [54]. One limitation of this study is that IFP data were based on mothers/caretakers reports and, thus, are subject to possible recall biases. Moreover, the presence of depressive symptoms may cause mothers to have more negative views about things around them, including household food security, child health and feeding practices. 


\section{Conclusions}

The findings of the present study demonstrate that in Ethiopia, infant feeding practices are generally poor, particularly, dietary diversity and consumption of iron rich foods are unacceptable low and two third of the households are food insecure. Moreover, prenatal and postnatal maternal depressive symptoms are quite common. Mainly, the study showed the longitudinal relationship of maternal depressive symptoms and other psychosocial factors with infant feeding practices, whereas postnatal depressive symptoms and IPV negatively associated with IFPs, perceived maternal social support and active social participation positively predicted infant feeding practices.

The implications of our findings for practice are to emphasize the need for prevention, early detection and treatment of postpartum depression, intimate partner violence and to strengthen household food security interventions, so that mothers are healthy, food secured and practicing appropriate infant feeding as per WHO infant feeding recommendation. Depression during pregnancy and postpartum often goes unrecognized by healthcare providers as changes in sleep, appetite and fatigue may be attributed to normal pregnancy and postpartum changes [99]. Furthermore, women often are reluctant to report changes related to depression, for example, Whitton and colleagues reported that over $80 \%$ of women diagnosed with postpartum depression had not reported symptoms to healthcare providers [100]. Similarly, IPV victims often experience feelings of shame and isolation and do not communicate openly to others that violence has occurred to them by their spouses [101].

Consequently, during pregnancy and postpartum period, women may particularly benefit from early screening for depression and intimate partner violence. However, screening without subsequent appropriate intervention may be counterproductive as women may find repeated screening difficult and potentially decrease their utilization of other health services. On the other hand, contrary to the expected result, the current study has shown that mothers in food insecure households may implement better infant feeding practices than those in food secure households. Based on this finding, advocating for policies to invest in and promote household food security solely as a means to improve infant feeding practices may have minimal impact without additional social and behavior change components.

In this regard, we recommend the Ethiopian Ministry of Health to integrate postnatal maternal depression and intimate partner violence screening into the routine postnatal care service and for the Ministry of Agriculture together with other relevant ministries, donors and implementers, to strengthen household food security interventions. Moreover, we recommend all relevant stakeholders particularly Ministry of Women Affaires to promote maternal social support and social participation. Overall, we concluded that a multitude of factors are related to IFPs and need coordinated, multi-sectoral and multi-stakeholder interventions.

\begin{abstract}
Abbreviations
Cl: Confidence interval; HITS: Hurt, Insult, Threaten and Scream; IFP: Infant feeding practice; IPV: Intimate partner violence; IYCF: Infant and young child feeding; MSS: Maternal social support; OR: Odds ratio; PHQ-9: Patient health questionnaire-9; USAID: United States Agency for International Development
\end{abstract}

\section{Acknowledgements}

We would like to thank the women who volunteered to participate in this study.

\section{Authors' contributions}

YK designed/implemented the study, analyzed the data and drafted the manuscript; SG \& TB designed/implemented the study and critically reviewed the final version of the manuscript; VS, EK, and HKB assisted data analysis and write up and critically reviewed the manuscript. All authors read and approved the final manuscript.

\section{Funding}

This research is made possible by the support of the American people through the United States Agency for International Development (USAID) under Agreement No. AID-663-A-11-00017. The contents of this document are the sole responsibility of the researchers \& do not necessarily reflect the views of USAID or the United States Government.

\section{Availability of data and materials}

The data that support the findings of this study are available from Tufts and Jimma Universities but restrictions apply to the availability of these data, which were used under license for the current study, and so are not publicly available. Data are however available from the authors upon reasonable request and with permission of Tufts and Jimma Universities.

\section{Declarations}

Ethics approval and consent to participate

The study was conducted in accordance with the WHO's ethical and safety recommendations for research on domestic violence against women [102]. The main principals to justify this research were also fulfilled according to the World Medical Association Declaration of Helsinki [103]. During data collection, all measures were taken to ensure that women could get support if it was deemed necessary. Study participants who were screened positive for depressive symptoms or IPV were referred to a nearby health facility for possible social and medical support. Ethical clearance was obtained from Jimma University ethical review board (IRB reference number: RPGC/264/ 2013) and Tufts University in the United States of America (IRB reference number: 11088). Informed written consent was obtained from all individual participants included in the study. All interviews were conducted in private and confidentiality was ensured for each study participants.

\section{Consent for publication}

Not applicable

\section{Competing interests}

We declare that we have no financial or non-financial competing interests.

\section{Author details}

${ }^{1}$ Institute of Nutrition Science (140a), University of Hohenheim, Stuttgart, Germany. ${ }^{2}$ Food Security Center, University of Hohenheim, Stuttgart, Germany. ${ }^{3}$ Department of Population and Family Health, College of Health Sciences, Jimma University, Jimma, Ethiopia. ${ }^{4}$ Tufts University, Friedman School of Nutrition Science and Policy, Boston, USA. ${ }^{5}$ Department of Gynecology, Faculty of Medicine, Martin-Luther University, Halle, Germany. ${ }^{6}$ Institute of Medical Epidemiology, Biostatistics, and Informatics, Faculty of Medicine, Martin-Luther University, Halle, Germany. 
Received: 2 December 2019 Accepted: 12 March 2021 Published online: 20 March 2021

\section{References}

1. WHO. Children: reducing mortality. 2019. Available from: https://www.who int/news-room/fact-sheets/detail/children-reducing-mortality

2. Martorell R, Khan LK, Schroeder DG. Reversibility of stunting: epidemiological findings in children from developing countries. Eur J Clin Nutr. 1994;48(Suppl 1):S45-57.

3. Bossavie L, Alderman H, Giles J, Mete C. The effect of height on earnings: is stature just a proxy for cognitive and non-cognitive skills? Washington, D.C: World Bank; 2017. Report No. 8254

4. Sudfeld CR, McCoy DC, Danaei G, Fink G, Ezzati M, Andrews KG, et al. Linear growth and child development in low- and middle-income countries: a meta-analysis. Pediatrics. 2015;135(5):e1266-75. https://doi.org/10.1542/ peds.2014-3111.

5. Addo OY, Stein AD, Fall CHD, Gigante DP, Guntupalli AM, Horta BL, Kuzawa CW, Lee N, Norris SA, Osmond C, Prabhakaran P, Richter LM, Sachdev HPS, Martorell R, and on Behalf of the Cohorts Group. Parental childhood growth and offspring birthweight: pooled analyses from four birth cohorts in low and middle income countries. Am J Hum Biol. 2015;27(1):99-105. https:// doi.org/10.1002/ajhb.22614.

6. Black RE, Victora CG, Walker SP, Bhutta ZA, Christian P, de Onis M, Ezzati M, Grantham-McGregor S, Katz J, Martorell R, Uauy R. Maternal and child undernutrition and overweight in low-income and middle-income countries. Lancet. 2013;382(9890):427-51. https://doi.org/10.1016/S0140-673 6(13)60937-X.

7. Pollitt E, Gorman KS, Engle PL, Rivera JA, Martorell R. Nutrition in early life and the fulfillment of intellectual potential. J Nutr. 1995;125(Suppl 4):1111S85 .

8. Victora CG, de Onis M, Hallal PC, Blossner M, Shrimpton R. Worldwide timing of growth faltering: revisiting implications for interventions. Pediatrics. 2010;125(3):e473-80. https://doi.org/10.1542/peds.2009-1519.

9. UNICEF. Infant and young child feeding: innocenti declaration 2005. 2005. Available from: www.ennonline.net/iycfinnocentideclaration2005

10. World Health Organization. Global strategy for infant and young child feeding. Geneva: WHO; 2003

11. Ethiopian Ministry of Health. National strategy for infant and young child feeding. 2004

12. Tadesse F, Alemayehu $Y$, Shine $S$, Asresahegn $H$, Tadesse $T$. Exclusive breastfeeding and maternal employment among mothers of infants from three to five months old in the Fafan zone, Somali regional state of Ethiopia: a comparative cross-sectional study. BMC Public Health. 2019;19: 1015.

13. Demilew YM, Tafere TE, Abitew DB. Infant and young child feeding practice among mothers with 0-24 months old children in slum areas of Bahir Dar City, Ethiopia. Int Breastfeed J. 2017;12(1):26. https://doi.org/10.1186/s13006017-0117-X.

14. CSA and ICF. ETHIOPIA Demographic and Health Survey. 2016.

15. Safari JG, Kimambo SC, Lwelamira JE. Feeding practices and nutritional status of infants in Morogoro municipality, Tanzania. Tanzan J Health Res. 2013;15(3):178-85. https://doi.org/10.4314/thrb.v15i3.5.

16. Caetano MC, Ortiz TTO, da Silva SGL, de Souza FIS, Sarni ROS. Complementary feeding: inappropriate practices in infants. J Pediatr. 2010; 86(3):196-201. https://doi.org/10.1590/S0021-75572010000300006.

17. World Health Organization. Infant and young child feeding: model chapter for textbooks for medical students and allied health professionals. Geneva: World Health Organization; 2009.

18. Dattilo AM, Carvalho RS, Feferbaum R, Forsyth S, Zhao A. Hidden realities of infant feeding: systematic review of qualitative findings from parents. Behav Sci. 2020;10(5):83. https://doi.org/10.3390/bs10050083.

19. Manyeh AK, Amu A, Akpakli DE, Williams JE, Gyapong M. Estimating the rate and determinants of exclusive breastfeeding practices among rural mothers in southern Ghana. Int Breastfeed J. 2020;15(1):7. https://doi.org/10.1186/s13 006-020-0253-6.

20. Abdurahman AA, Chaka EE, Bule MH, Niaz K. Magnitude and determinants of complementary feeding practices in Ethiopia: a systematic review and meta-analysis. Heliyon. 2019;5(7):e01865. https://doi.org/10.1016/j.heliyon.201 9.e01865.

21. Temesgen $H$, Negesse A, Woyraw W, Getaneh T, Yigizaw M. Prelacteal feeding and associated factors in Ethiopia: systematic review and meta- analysis. Int Breastfeed J. 2018;13(1):49. https://doi.org/10.1186/s13006-0180193-6.

22. Temesgen $H$, Negesse A, Woyraw W, Mekonnen N. Dietary diversity feeding practice and its associated factors among children age 6-23 months in Ethiopia from 2011 up to 2018: a systematic review and meta-analysis. Ital J Pediatr. 2018;44(1):109. https://doi.org/10.1186/s13052-018-0567-9.

23. Santana GS, Giugliani ERJ, de Vieira TO, Vieira GO. Factors associated with breastfeeding maintenance for 12 months or more: a systematic review. J Pediatr. 2018;94:104-22.

24. Esteves TMB, Daumas RP, de Oliveira MIC, Andrade CA de F de, Leite IC. Factors associated to breastfeeding in the first hour of life: systematic review. Rev Saúde Pública. 2014;48(4):697-708. https://doi.org/10.1590/ S0034-8910.2014048005278.

25. Machado MCM, Assis KF, de Oliveira FCC, Ribeiro AQ, Araújo RMA, Cury AF, et al. Determinants of the exclusive breastfeeding abandonment: psychosocial factors. Rev Saúde Pública. 2014;48(6):985-94. https://doi.org/1 0.1590/S0034-8910.2014048005340.

26. O'Brien M, Buikstra E, Hegney D. The influence of psychological factors on breastfeeding duration. J Adv Nurs. 2008;63(4):397-408. https://doi.org/1 0.1111/j.1365-2648.2008.04722.x.

27. Dunn S, Davies B, McCleary L, Edwards N, Gaboury I. The relationship between vulnerability factors and breastfeeding outcome. J Obstet Gynecol Neonatal Nurs JOGNN. 2006;35(1):87-97. https://doi.org/10.1111/j.15526909.2006.00005.x.

28. Hoche S, Meshesha B, Wakgari N. Sub-optimal breastfeeding and its associated factors in rural communities of Hula District, southern Ethiopia: a cross-sectional study. Ethiop J Health Sci. 2018;28(1):49-62. https://doi.org/1 0.4314/ejhs.v28i1.7.

29. Cato K, Sylvén SM, Georgakis MK, Kollia N, Rubertsson C, Skalkidou A. Antenatal depressive symptoms and early initiation of breastfeeding in association with exclusive breastfeeding six weeks postpartum: a longitudinal population-based study. BMC Pregnancy Childbirth. 2019;19(1): 49. https://doi.org/10.1186/s12884-019-2195-9.

30. Slomian J, Honvo G, Emonts $P$, Reginster J-Y, Bruyère $O$. Consequences of maternal postpartum depression: a systematic review of maternal and infant outcomes. Women Health. 2019;15:174550651984404. https://doi.org/10.11 $77 / 1745506519844044$

31. Dias CC, Figueiredo B. Breastfeeding and depression: a systematic review of the literature. J Affect Disord. 2015;171:142-54. https://doi.org/10.1016/j.jad.2 014.09.022.

32. Figueiredo B, Canário C, Field T. Breastfeeding is negatively affected by prenatal depression and reduces postpartum depression. Psychol Med. 2014;44(5):927-36. https://doi.org/10.1017/S0033291713001530.

33. Wallenborn JT, Joseph A-C, Graves WC, Masho SW. Prepregnancy depression and breastfeeding duration: a look at maternal age. J Pregnancy. 2018;2018:1-7.

34. Ali NB, Tahsina T, Hoque DME, Hasan MM, lqbal A, Huda TM, et al. Association of food security and other socio-economic factors with dietary diversity and nutritional statuses of children aged 6-59 months in rural Bangladesh. Cardoso MA, editor. PLoS One. 2019;14:e0221929.

35. Marinda PA, Genschick S, Khayeka-Wandabwa C, Kiwanuka-Lubinda R, Thilsted SH. Dietary diversity determinants and contribution of fish to maternal and under-five nutritional status in Zambia. PLoS One. 2018;13(9): e0204009. https://doi.org/10.1371/journal.pone.0204009.

36. Miller-Graff LE, Ahmed AH, Paulson JL. Intimate partner violence and breastfeeding outcomes in a sample of low-income women. J Hum Lact. 2018;34(3):494-502. https://doi.org/10.1177/0890334418776217.

37. Zureick-Brown S, Lavilla K, Yount KM. Intimate partner violence and infant feeding practices in India: a cross-sectional study: IPV and infant feeding practices in India. Matern Child Nutr. 2015;11(4):792-802. https://doi.org/1 0.1111/men.12057.

38. Misch ES, Yount KM. Intimate partner violence and breastfeeding in Africa. Matern Child Health J. 2014;18(3):688-97. https://doi.org/10.1007/s10995013-1294-x.

39. Ickes SB, Wu M, Mandel MP, Roberts AC. Associations between social support, psychological well-being, decision making, empowerment, infant and young child feeding, and nutritional status in Ugandan children ages 0 to 24 months. Matern Child Nutr. 2018;14(1):e12483. https://doi.org/10.1111/ mcn.12483.

40. Mukuria AG, Martin SL, Egondi T, Bingham A, Thuita FM. Role of social support in improving infant feeding practices in western Kenya: a quasi- 
experimental study. Glob Health Sci Pract. 2016;4(1):55-72. https://doi.org/1 0.9745/GHSP-D-15-00197.

41. Thomas JL, Lewis JB, Martinez I, Cunningham SD, Siddique M, Tobin JN, Ickovics JR. Associations between intimate partner violence profiles and mental health among low-income, urban pregnant adolescents. BMC Pregnancy Childbirth. 2019;19(1):120. https://doi.org/10.1186/s12884-019-22 56-0.

42. Woldetensay YK, Belachew T, Biesalski HK, Ghosh S, Lacruz ME, Scherbaum $V$, Kantelhardt EJ. The role of nutrition, intimate partner violence and social support in prenatal depressive symptoms in rural Ethiopia: community based birth cohort study. BMC Pregnancy Childbirth. 2018;18(1):374. https:// doi.org/10.1186/s12884-018-2009-5.

43. Rogathi JJ, Manongi R, Mushi D, Rasch V, Sigalla GN, Gammeltoft T, Meyrowitsch DW. Postpartum depression among women who have experienced intimate partner violence: a prospective cohort study at Moshi, Tanzania. J Affect Disord. 2017;218:238-45. https://doi.org/10.1016/j.jad.2017. 04.063.

44. Miura A, Fujiwara T. Intimate partner violence during pregnancy and postpartum depression in Japan: a cross-sectional study. Front Public Health. 2017;5:81. https://doi.org/10.3389/fpubh.2017.00081.

45. Kothari CL, Liepman MR, Shama Tareen R, Florian P, Charoth RM, Haas SS, McKean JW, Moe A, Wiley J, Curtis A. Intimate partner violence associated with postpartum depression, regardless of socioeconomic status. Matern Child Health J. 2016;20(6):1237-46. https://doi.org/10.1 007/s10995-016-1925-0.

46. East CE, Biro MA, Fredericks S, Lau R. Support during pregnancy for women at increased risk of low birthweight babies. Cochrane Database Syst Rev. 2019:CD000198.

47. Gan Y, Xiong R, Song J, Xiong X, Yu F, Gao W, Hu H, Zhang J, Tian Y, Gu X, Zhang J, Chen D. The effect of perceived social support during early pregnancy on depressive symptoms at 6 weeks postpartum: a prospective study. BMC Psychiatry. 2019;19(1):232. https://doi.org/10.1186/s12888-019-21 88-2.

48. Milgrom J, Hirshler Y, Reece J, Holt C, Gemmill AW. Social support-a protective factor for depressed perinatal women? Int J Environ Res Public Health. 2019;16(8):1426. https://doi.org/10.3390/ijerph16081426.

49. Tang $X, L u Z$, , Hu D, Zhong $X$. Influencing factors for prenatal stress, anxiety and depression in early pregnancy among women in Chongqing, China. J Affect Disord. 2019;253:292-302. https://doi.org/10.1016/j.jad.2019.05.003.

50. Chaudhary S, Govil S, Lala M, Yagnik H. Infant and young child feeding index and its association with nutritional status: a cross-sectional study of urban slums of Ahmedabad. J Fam Community Med. 2018;25(2):88-94. https://doi.org/10.4103/jfcm.JFCM_82_17.

51. Lohia N, Udipi SA. Infant and child feeding index reflects feeding practices, nutritional status of urban slum children. BMC Pediatr. 2014;14(1):290. https://doi.org/10.1186/s12887-014-0290-7.

52. Ruel MT, Menon P. Child feeding practices are associated with child nutritional status in Latin America: innovative uses of the demographic and health surveys. J Nutr. 2002;132(6):1180-7. https://doi.org/10.1093/jn/132. 6.1180.

53. Reinbott A, Kuchenbecker J, Herrmann J, Jordan I, Muehlhoff E, Kevanna O, Krawinkel M. A child feeding index is superior to WHO IYCF indicators in explaining length-for-age Z-scores of young children in rural Cambodia. Paediatr Int Child Health. 2015;35(2):124-34. https://doi.org/10.1179/204 6905514Y.0000000155.

54. World Health Organization (WHO). Indicators for assessing infant and young child feeding practices: conclusions of a consensus meeting held 6-8 November 2007 in Washington D.C., USA. Washington, D.C: World Health Organization (WHO); 2008.

55. Spitzer RL. Validation and utility of a self-report version of PRIME-MDThe PHQ primary care study. JAMA. 1999;282(18):1737-44. https://doi.org/10.1 001/jama.282.18.1737.

56. Kroenke K, Spitzer RL, Williams JBW. The PHQ-9: validity of a brief depression severity measure. J Gen Intern Med. 2001;16:606-13 [cited 2014 Nov 4]. Available from: http://link.springer.com/10.1046/j.1525-1497.2001.016009606.x.

57. Woldetensay YK, Belachew T, Tesfaye M, Spielman K, Biesalski HK, Kantelhardt EJ, et al. Validation of the Patient Health Questionnaire (PHQ-9) as a screening tool for depression in pregnant women: Afaan Oromo version. LoBello S, editor. PLoS One. 2018;13:e0191782.

58. Coates J, Swindale A, Bilinsky P. Household food insecurity access scale (HFIAS) for measurement of food access: indicator guide. Washington, D.C;
2007. Available from: http://www.fao.org/fileadmin/user_upload/eufao-fsi4 $\mathrm{dm} /$ doc-training/hfias.pdf

59. Deshpande NA, Lewis-O'Connor A. Screening for intimate partner violence during pregnancy. Rev Obstet Gynecol. 2013;6(3-4):141-8.

60. Mercer RT, Ferketich SL. Stress and social support as predictors of anxiety and depression during pregnancy. ANS Adv Nurs Sci. 1988;10(2):26-39. https://doi.org/10.1097/00012272-198801000-00008.

61. Pope CJ, Mazmanian D. Breastfeeding and postpartum depression: an overview and methodological recommendations for future research. Depress Res Treat. 2016;2016:1-9. https://doi.org/10.1155/2016/4765310.

62. García-Moreno C, Pallitto C, Devries K, Stöckl H, Watts C, Abrahams N. Global and regional estimates of violence against women: prevalence and health effects of intimate partner violence and non-partner sexual violence. Geneva: World Health Organization; 2013.

63. Bitew T, Hanlon C, Medhin G, Fekadu A. Antenatal predictors of incident and persistent postnatal depressive symptoms in rural Ethiopia: a population-based prospective study. Reprod Health. 2019;16(1):28. https:// doi.org/10.1186/s12978-019-0690-0.

64. McEwen BS. Protective and damaging effects of stress mediators: central role of the brain. Dialogues Clin Neurosci. 2006;8(4):367-81.

65. Caleyachetty R, Uthman OA, Bekele HN, Martín-Cañavate R, Marais D, Coles J, Steele B, Uauy R, Koniz-Booher P. Maternal exposure to intimate partner violence and breastfeeding practices in 51 low-income and middle-income countries: a population-based cross-sectional study. PLoS Med. 2019;16(10): e1002921. https://doi.org/10.1371/journal.pmed.1002921.

66. Lumbiganon P, Martis R, Laopaiboon M, Festin MR, Ho JJ, Hakimi M. Antenatal breastfeeding education for increasing breastfeeding duration. Cochrane Database Syst Rev. 2016;12:CD006425.

67. Krug EG, Mercy JA, Dahllberg LL, Zwi AB. World report on violence and health. Lancet. 2002;360(9339):1083-8. https://doi.org/10.1016/S0140-6736(02)11133-0.

68. Musa A, Chojenta C, Geleto A, Loxton D. The associations between intimate partner violence and maternal health care service utilization: a systematic review and meta-analysis. BMC Womens Health. 2019;19(1):36. https://doi. org/10.1186/s12905-019-0735-0.

69. Yount KM, DiGirolamo AM, Ramakrishnan U. Impacts of domestic violence on child growth and nutrition: a conceptual review of the pathways of influence. Soc Sci Med 1982. 2011;72:1534-54.

70. Mechanic MB, Weaver TL, Resick PA. Mental health consequences of intimate partner abuse: a multidimensional assessment of four different forms of abuse. Violence Women. 2008;14(6):634-54. https://doi.org/10.11 77/1077801208319283.

71. Scott JA, Binns CW, Graham Kl, Oddy WH. Temporal changes in the determinants of breastfeeding initiation. Birth Berkeley Calif. 2006;33(1):3745. https://doi.org/10.1111/j.0730-7659.2006.00072.x.

72. Macharia TN, Ochola S, Mutua MK, Kimani-Murage EW. Association between household food security and infant feeding practices in urban informal settlements in Nairobi, Kenya. J Dev Orig Health Dis. 2018;9(1):20-9. https:// doi.org/10.1017/S2040174417001064.

73. Owais A, Kleinbaum DG, Suchdev PS, Faruque A, Das SK, Schwartz B, Stein AD. Household food security and infant feeding practices in rural Bangladesh. Public Health Nutr. 2016;19(10):1875-81. https://doi.org/10.101 7/S1368980015003195

74. Agbadi P, Urke HB, Mittelmark MB. Household food security and adequacy of child diet in the food insecure region north in Ghana. PLoS One. 2017; 12(5):e0177377. https://doi.org/10.1371/journal.pone.0177377.

75. Hanselman B, Ambikapathi R, Mduma E, Svensen E, Caulfield LE, Patil CL. Associations of land, cattle and food security with infant feeding practices among a rural population living in Manyara, Tanzania. BMC Public Health. 2018;18(1):159. https://doi.org/10.1186/s12889-018-5074-9.

76. Wyatt AJ, Yount KM, Null C, Ramakrishnan U, Webb GA. Dairy intensification, mothers and children: an exploration of infant and young child feeding practices among rural dairy farmers in Kenya: dairy intensification and child feeding practices. Matern Child Nutr. 2015;11(1):88-103. https://doi.org/1 $0.1111 / \mathrm{mcn} .12074$

77. Valid International. Empowering new generations to improve nutrition and economic opportunities (ENGINE): impact assessment. Ethiopia; 2016.

78. Waswa LM, Jordan I, Herrmann J, Krawinkel MB, Keding GB. Communitybased educational intervention improved the diversity of complementary diets in western Kenya: results from a randomized controlled trial. Public Health Nutr. 2015;18(18):3406-19. https://doi.org/1 $0.1017 / \$ 1368980015000920$ 
79. Kuchenbecker J, Reinbott A, Mtimuni B, Krawinkel MB, Jordan I. Nutrition education improves dietary diversity of children 6-23 months at community-level: results from a cluster randomized controlled trial in Malawi. PLoS One. 2017;12(4):e0175216. https://doi.org/10.1371/journal. pone.0175216

80. Seeman TE, Singer BH, Ryff CD, Dienberg G, Levy-Storms L. Socia relationships, gender, and allostatic load across two age cohorts. Psychosom Med. 2002;64(3):395-406. https://doi.org/10.1097/00006842-2002 05000-00004.

81. McEwen B, Rasgon N. Brain and body on stress: allostatic load and mechanisms for depression and dementia. Depress Syst IIIn. Strain JJ, Blumenfield M, editors. Oxford: Oxford University Press; 2018.

82. Kobrosly RW, van Wijngaarden E, Seplaki CL, Cory-Slechta DA, Moynihan J. Depressive symptoms are associated with allostatic load among community-dwelling older adults. Physiol Behav. 2014;123:223-30. https:// doi.org/10.1016/j.physbeh.2013.10.014.

83. Sanghvi T, Martin L, Hajeebhoy N, Abrha TH, Abebe Y, Haque R, Tran HTT, Roy S. Strengthening systems to support mothers in infant and young child feeding at scale. Food Nutr Bull. 2013;34(3_suppl2):S156-68. https://doi. org/10.1177/15648265130343S203.

84. Giannì ML, Bezze E, Sannino P, Stori E, Plevani L, Roggero P, Agosti M, Mosca F. Facilitators and barriers of breastfeeding late preterm infants according to mothers' experiences. BMC Pediatr. 2016;16(1):179. https://doi. org/10.1186/s12887-016-0722-7.

85. Rayfield S, Oakley L, Quigley MA. Association between breastfeeding support and breastfeeding rates in the UK: a comparison of late preterm and term infants. BMJ Open. 2015;5(11):e009144. https://doi.org/10.1136/ bmjopen-2015-009144.

86. Demirci JR, Sereika SM, Bogen D. Prevalence and predictors of early breastfeeding among late preterm mother-infant dyads. Breastfeed Med. 2013;8(3):277-85. https://doi.org/10.1089/bfm.2012.0075.

87. Fanaro S, Borsari G, Vigi V. Complementary feeding practices in preterm infants: an observational study in a cohort of Italian infants. J Pediatr Gastroenterol Nutr. 2007;45(Suppl 3):S210-4. https://doi.org/10.1097/01.mpg. 0000302974.90867.f1.

88. Norris FJ, Larkin MS, Williams CM, Hampton SM, Morgan JB. Factors affecting the introduction of complementary foods in the preterm infant. Eur J Clin Nutr. 2002;56(5):448-54. https://doi.org/10.1038/sj.ejcn.1601336.

89. Paintal K, Aguayo VM. Feeding practices for infants and young children during and after common illness. Evidence from South Asia. Matern Child Nutr. 2016;12(Suppl 1):39-71.

90. Abegaz NT, Berhe H, Gebretekle GB. Mothers/caregivers healthcare seeking behavior towards childhood illness in selected health centers in Addis Ababa, Ethiopia: a facility-based cross-sectional study. BMC Pediatr. 2019;19:220.

91. Habibi M, Laamiri FZ, Aguenaou H, Doukkali L, Mrabet M, Barkat A. The impact of maternal socio-demographic characteristics on breastfeeding knowledge and practices: an experience from Casablanca, Morocco. Int J Pediatr Adolesc Med. 2018;5(2):39-48. https://doi.org/10.1016/j.jpam.2018. 01.003 .

92. Eshete T, Kumera G, Bazezew Y, Mihretie A, Marie T. Determinants of inadequate minimum dietary diversity among children aged 6-23 months in Ethiopia: secondary data analysis from Ethiopian Demographic and Health Survey 2016. Agric Food Secur. 2018;7(1):66. https://doi.org/10.1186/ s40066-018-0219-8.

93. Belew AK, Ali BM, Abebe Z, Dachew BA. Dietary diversity and meal frequency among infant and young children: a community based study. Ital J Pediatr. 2017:43(1):73. https://doi.org/10.1186/s13052-017-0384-6.

94. Dangura D, Gebremedhin S. Dietary diversity and associated factors among children 6-23 months of age in Gorche district, Southern Ethiopia: Crosssectional study. BMC Pediatr. 2017;17:6.

95. Greiner T. Exclusive breastfeeding: measurement and indicators. Int Breastfeed J. 2014;9(1):18. https://doi.org/10.1186/1746-4358-9-18.

96. Noel-Weiss J, Boersma S, Kujawa-Myles S. Questioning current definitions for breastfeeding research. Int Breastfeed J. 2012;7(1):9. https://doi.org/10.11 86/1746-4358-7-9.

97. Debra HJ. Complexities and subtleties in the measurement and reporting of breastfeeding practices. Int Breastfeed J. 2011;6(1):5. https://doi.org/10.11 86/1746-4358-6-5.

98. Agampodi SB, Agampodi TC, de Silva A. Exclusive breastfeeding in Sri Lanka: problems of interpretation of reported rates. Int Breastfeed J. 2009; 4(1):14. https://doi.org/10.1186/1746-4358-4-14.
99. ACOG. Screening for perinatal depression. 2018. [cited 2019 Sep 12]. Available from: https://www.acog.org/-/media/Committee-Opinions/ Committee-on-Obstetric-Practice/co757.pdf?dmc $=1 \& t s=201912$ 09T1434341360

100. Whitton A, Warner R, Appleby L. The pathway to care in post-natal depression: women's attitudes to post-natal depression and its treatment. $\mathrm{Br}$ J Gen Pract. 1996;46(408):427-8.

101. Ellsberg M, Peña R, Herrera A, Liljestrand J, Winkvist A. Candies in hell: women's experiences of violence in Nicaragua. Soc Sci Med. 2000;51(11): 1595-610. https://doi.org/10.1016/S0277-9536(00)00056-3.

102. World Health Organization. Putting women first: ethical and safety recommendations for research on domestic violence against women. Geneva; 2001. [cited 2017 Feb 1]. Available from: https://www.who.int/ gender/violence/womenfirtseng.pdf

103. World Medical Association. World medical association declaration of Helsinki: ethical principles for medical research involving human subjects. JAMA. 2013;310:2191-4.

\section{Publisher's Note}

Springer Nature remains neutral with regard to jurisdictional claims in published maps and institutional affiliations.

Ready to submit your research? Choose BMC and benefit from:

- fast, convenient online submission

- thorough peer review by experienced researchers in your field

- rapid publication on acceptance

- support for research data, including large and complex data types

- gold Open Access which fosters wider collaboration and increased citations

- maximum visibility for your research: over $100 \mathrm{M}$ website views per year

At BMC, research is always in progress.

Learn more biomedcentral.com/submissions 